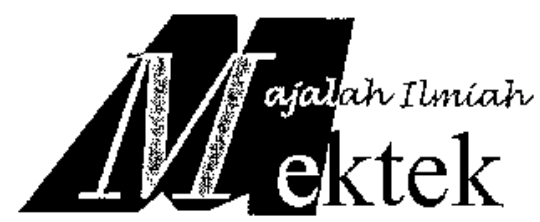

\title{
ANALISIS ALIRAN DI BELOKAN SALURAN \\ (STUDI MODEL FISIK DAN MATEMATIK UNTUK MENJELASKAN FENOMENA GERUSAN DI SUNGAI PALU)
}

\author{
M. Galib Ishak* dan I Gede Tunas*
}

\begin{abstract}
Local scoruring phenomena in river bend, generally affected from secondary and centrifugal flow. The chracteristic of flow surrounding the curve created eddies wich is showed inconsistency of flow model. The effect of those flow are the differentiation of water level at closed out of divert channel. The numerical model and laboratory modeling was conducted in all research aspect. Some model used to calibrate the laboratory work and it compared with numerical model. The result of the research showed the cross section deformation. The transverse duct deformed market as the water level rise in turning canal and it is indicated from Froude number variation. The increased of surface leval around the river bend was correlated to velocity. And The consequences of surface rise and flow accumulation at stream curve is river bank erosion.
\end{abstract}

Keyword: River bend, water level rise, erosions

\section{Pendahuluan}

Fenomena gerusan lokal (local scouring) yang terjadi di sungai terutama di sekitar belokan, umumnya sering terjadi akibat arus sekunder dan gaya sentrifugal yang bekerja pada aliran. Secara umum karakteristik aliran di sekitar belokan, ditandai dengan tidak liniernya pola arus tetapi membentuk pusaran-pusaran (eddies). Akibat yang ditimbulkan oleh arus dan gaya tersebut adalah terjadi perbedaan elevasi muka air pada sisi luar belokan dan sisi dalam belokan, dalam hal ini terjadi peningkatan elevasi muka air pada sisi luar belokan. Arti dari fenomena tersebut adalah karakteristik aliran di sekitar belokan adalah suatau permasalahan kompleks yang harus dianalisis dalam dua matra (2D) atau tiga matra (3D), dan sangat tidak rasional apabila dianalisis dalam 1D (Jansen, 1979).

Dalam kebanyakan kasus perencanaan dan perancangan, analisis aliran di sungai menggunakan konsep 1D sehingga mengabaikan fenomena arus sekunder dan gaya sentrifugal yang bekerja. Pengabaian ini menyebabkan tidak diperhitungkannya kenaikan elevasi muka air di sebelah sisi luar belokan, sehingga seringkali elevasi tanggul/talud di sekitar belokan terlampaui dan menyebabkan terjadinya gerusan di sekitar belokan seperti yang terjadi di Sungai Palu bagian hilir. Penelitian ini bertujuan untuk memepelajari karakteristik aliran di sekitar belokan untuk menjelaskan fenomena gerusan di Sungai Palu hilir.

\section{Tinjauan Pustaka}

2.1 Teori aliran di belokan saluran Sebagaimana telah diketahui, gerakan air pada saluran terbuka yang membelok akan mengalami gaya lemparan ke sisi luar belokan yang di sebut dengan gaya sentripetal (Legono, 2003). Pada kondisi ini aliran akan berusaha bergerak keluar, tetapi angkutan massa total pada arah transversal harus sama dengan nol. Fenomena seperti inilah yang disebut fenomena alira helokoidal yaitu suatu fenomena aliran utama searah aliran dipengaruhi oleh hadirnya aliran sekunder.

Dengan adanya fenomena ini maka terjadi interaksi antara tegangan geser (akibat aliran helikoidal) dengan tegangan geser yang menahan (akibat sifat erodibilitas penampang basah saluran) (Jansen, 1979), dampak utama akibat dari fenomena aliran helikoidal adalah terjadinya

\footnotetext{
* Staf Pengajar Jurusan Teknik Sipil Fakultas Teknik Universitas Tadulako, Palu
} 
serangan pada tebing saluran pada sisi luar belokan, serta pengendapan atau sedimentasi pada dasar saluran di dekat sisi dalam belokan.

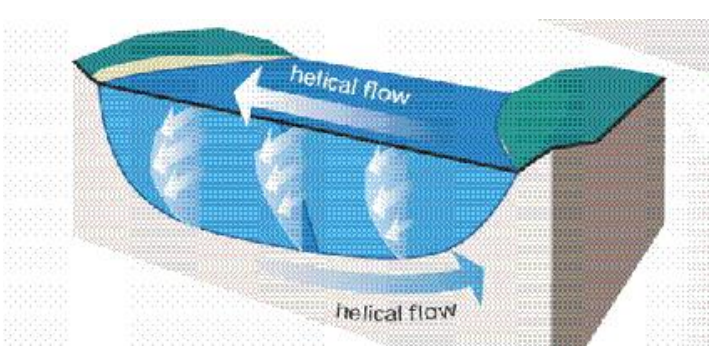

Gambar 1. Aliran helikoidal di belokan sungai

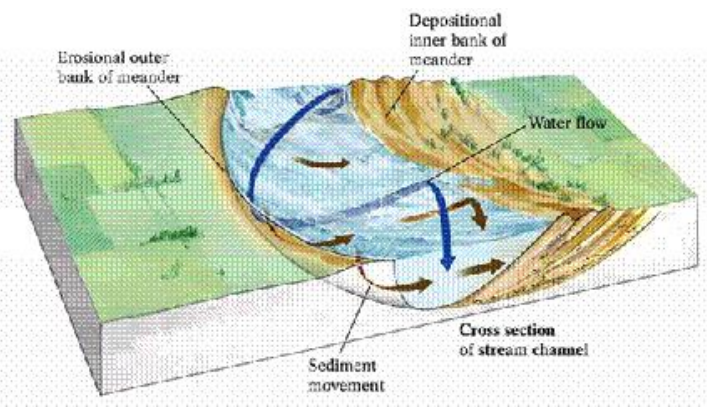

Gambar 2. Erosi dan deposisi di belokan sungai

\subsection{Persamaan pengatur}

Untuk mendeskripsikan fenomena aliran di belokan saluran/sungai, beberapa persamaan gerakan fluida yang dapat diacu adalah persamaan kontinuitas (keseimbangan massa) dan persamaan Navier-Stokes, serta beberapa persamaan turunan yang lain seperti persamaan Newton, Reynolds dan Froude. Merujuk pada koordinat silender yang dapat mewakili pendeskripsian belokan saluran/sungai, persamaan kontinuitas (Yen, 1971) dari beberapa persamaan di bawah hingga menghasilkan kemirngan permukaan air ( $\mathrm{Sr}$ dan Hrc) sebagai berikut:

$$
\frac{\partial \rho}{\partial t}+\frac{1}{r} \frac{\partial}{\partial r}(r \rho u)+\frac{1}{r} \frac{\partial}{\partial \theta}(\rho v)+\frac{\partial}{\partial z}(\rho w)=0
$$

Untuk lebih mudah pemahaman lebih lanjut, persamaan kontinuitas sebagaimana dituliskan pada persamaan (1) diterapkan pada kasus aliran tunak (permanen) dan disederhanakan menjadi :

$$
\frac{1}{r} \frac{\partial}{\partial r} r u+\frac{1}{r} \frac{\partial}{\partial \theta} v+\frac{\partial}{\partial z} w=0
$$

Persamaan lengkap yang menjelaskan gerakan elemen fluida viskos dalam pengaruh gaya gravitasi dinyatakan dalam persamaan NavierStokes, dalam bentuk persamaan sebagai berikut:

$$
\begin{aligned}
& \rho \frac{D w}{D t}=-\frac{\partial P}{\partial z}\left(2 \mu \frac{\partial w}{\partial z}-\frac{2}{3} \mu \operatorname{div} v\right) \\
& +\frac{1}{r} \frac{\partial}{\partial r}\left[\mu r\left(\frac{\partial v}{\partial z}+\frac{\partial u}{\partial r}\right)\right]+\frac{1}{r} \frac{\partial}{\partial \theta} \\
& {\left[\mu\left(\frac{1}{r} \frac{\partial w}{\partial \theta}+\frac{\partial u}{\partial z}\right)\right]+\rho g z}
\end{aligned}
$$

dimana

derivativ $\frac{D}{D t}=v \frac{\partial}{\partial r}+\frac{u}{r} \frac{\partial}{\partial \theta}+w \frac{\partial}{\partial z}+\frac{\partial}{\partial t} \quad$ disederhanakan dengan menggunakan persamaan kontinuitas :

$$
\begin{aligned}
& \frac{D w}{D t}=-\frac{1}{\rho} \frac{\partial P}{\partial z}+v\left(\frac{\partial^{2} w}{\partial r^{2}}+\frac{1}{r^{2}} \frac{\partial^{2} w}{\partial \theta^{2}}+\frac{\partial^{2} w}{\partial \theta^{2}}\right) \\
& +\rho g z
\end{aligned}
$$

2.3 Permukaan air pada penampang melintang saluran

Profil permukaan air pada suatu belokan saluran dinyatakan selengkapnya dengan persamaan gerak, yang diturunkan dari persamaan Reynold. Selanjutnya berdasarkan persamaan Reynold, dapat ditentukan kemiringan permukaan air sepanjang arah melintang saluran dengan teknik integrasi.

$$
s_{r}=\frac{1}{g h}\left[\int_{z 0}^{z 1} \frac{\bar{u}^{2}}{r} d z-\bar{u}_{t}^{2} \sin \theta\right]
$$


Merujuk pada persamaan (4), kemiringan arah melintang saluran di suatu titik di belokan dapat dituliskan:

$$
s_{r}=\frac{u_{m}^{2}}{2 g r}-2\left\{\begin{array}{l}
\frac{r}{h}\left(\frac{\bar{u}_{\tau}}{u_{m}}\right)^{2} \sin \phi+ \\
\int_{z_{0} / h}^{z_{1} / h} 2\left[\begin{array}{l}
\left(\frac{\bar{u}}{u_{m}}\right)^{2} \\
-\frac{\bar{u}}{u_{m}} \frac{\partial\left(\frac{\bar{v}}{u_{m}}\right)}{\partial \theta}
\end{array}\right] d\left(\frac{z}{h}\right)
\end{array}\right\}
$$

Perbedaan permukaan air arah melintang terhadap jari-jari pusat saluran, dapat dinyatakan dengan integral sebagai berikut :

$$
H_{r c}=\int_{r c}^{r} s_{r} d r=\frac{u_{m}^{r}}{2 g} \int_{r c}^{r} \frac{C_{r}}{r} d r
$$

dimana $\mathrm{rc}=$ jari-jari pusat saluran, $\mathrm{r}=$ koordinat radial pada titik tertentu sepanjang lebar saluran, $\mathrm{H}_{\mathrm{rc}}=$ perbedaan elevasi permukaan air di antara potongan $r$ dan $r c$ pada penampang melintang.

\section{Metode Penelitian}

\subsection{Pemodelan numerik}

Pemodelan numerik dilakukan terhadap persamaan differensial kontinuitas (keseimbangan massa) dan Navier-Stokes untuk kasus aliran tunak (steady flow). Penyelesaian persamaan tersebut dilakukan dengan integrasi numerik dan membagi pias menjadi beberap segmen dan grid-grid.

\subsection{Pemodelan laboratorium}

Pemodelan di laboratorium dimaksudkan untuk mengkalibrasi/ membandingkan hasil hitungan numerik dengan dasar tetap (fixed bed). Adapaun peralatan dan prosedur percobaan adalah sebagai berikut ini :

a. Saluran berpenampang segi empat berukuran lebar $50 \mathrm{~cm}$ dan tinggi $30 \mathrm{~cm}$ dengan sudut belokan $90^{\circ}$ terbuat dari kaca pada bagian lurus dan fiber gelas pada bagian belokan.

b. Meteran taraf (point gauge), untuk mengukur ketinggian muka air. Muka air diukur selama masa running (sumulasi) pada arah melintang saluran dibelokan.

c. Stop watch, untuk mengukur waktu yang diperlukan untuk menampung debit aliran pada akhir saluran. Untuk maksud ini, debit air ditampung dan dikur waktu penampungannya dan juga diukur volumenya. Berdasarkan informasi waktu dan volume, maka dapat diketahui kecepatan rerata aliran di saluran.

d. Laser dopler (alat pengukur kecepatan dengan laser) dan current meter, untuk mengukur distribusi kecepatan aliran (vertikal dan horisontal) baik pada saluran yang lurus maupun pada belokan saluran. Alat ini dapat digerakkan dan dilakukan pengukuran distribusi kecepatan vertikal terutama di belokan saluran.

e. Sumber air (pompa). Debit air dialirkan dari pompa yang telah dilkalibrasi sebelumnya. Running (simulasi) dilakukan untuk beberapa kali besaran debit.

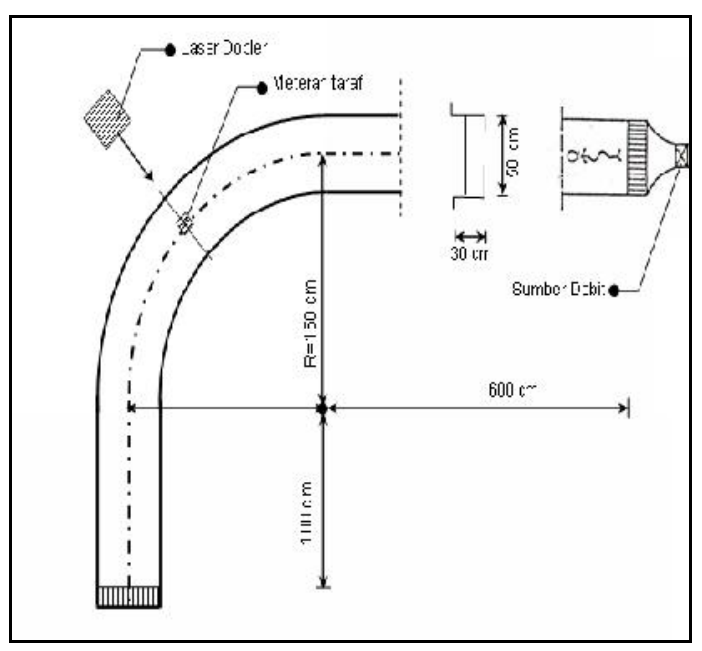

Gambar 3. Tampak atas saluran laboratorium

\section{Hasil dan Pembahasan}

4.1 Kemiringan muka air di belokan

Berdasarkan hasil uji laboratorium dan hitungan numerik, menunjukkan karakter yang sama, dimana terjadi perbedaan elelvasi muka air pada profil melintang saluran di belokan. Pada pengukuran di laboratorium untuk debit yang sama, pada bilangan Froud yang kecil perbedaan ketinggian muka air kecil dan pada bilangan Froude yang besar menununjukkan ketinggian muka air yang besar. Dengan demikian dapat katakan bahwa 
kenaikan permukaan air berbanding lurus terhadap kecepatan.

Pengukuran dan hitungan numerik (Galib, 1992) yang di lakukan pada interval sudut $10^{\circ}$, yakni $0^{\circ}$ pada awal belokan saluran sampai $90^{\circ}$ di akhir belokan saluran sebagaimana gambar di bawah ini.

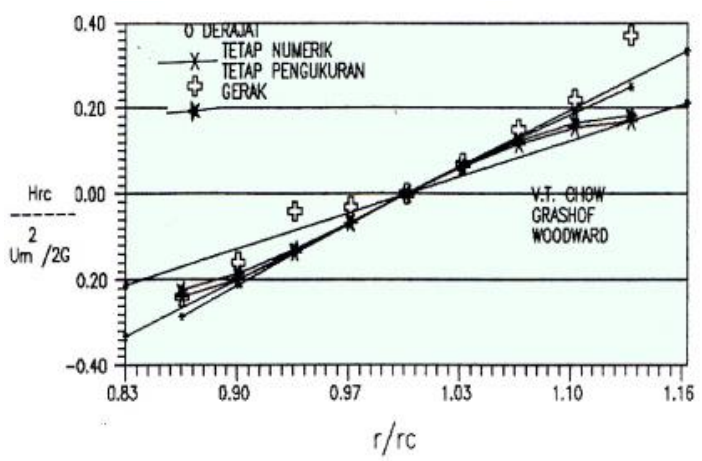

Gambar 4. Profil muka air melintang pada sudut $0^{\circ}$

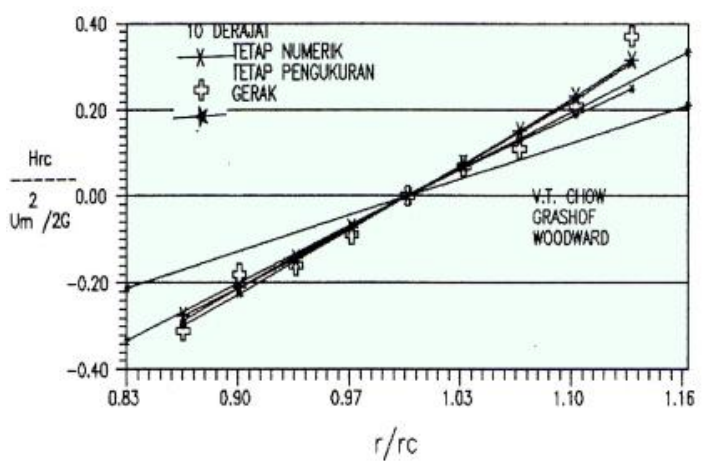

Gambar 5. Profil muka air melintang pada sudut $10^{\circ}$

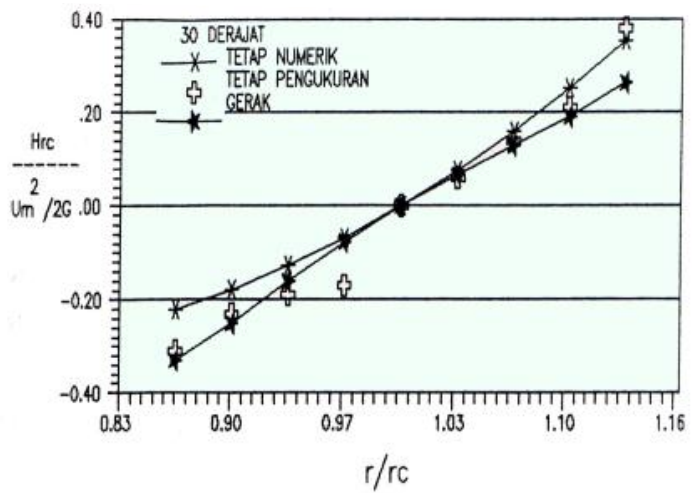

Gambar 6. Profil muka air melintang pada sudut $20^{\circ}$

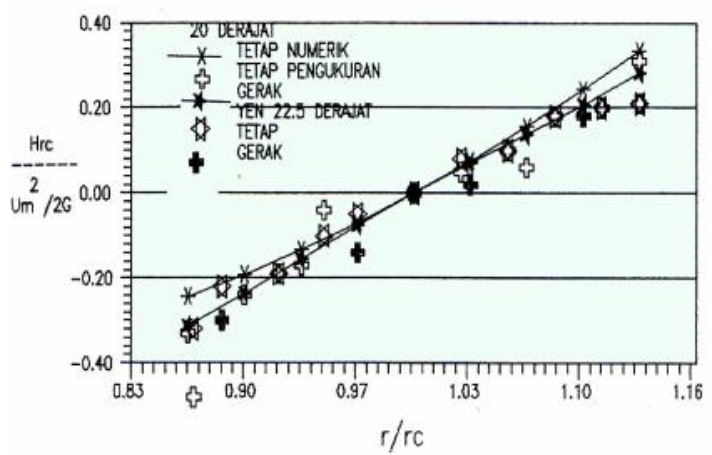

Gambar 7. Profil muka air melintang pada sudut $30^{\circ}$

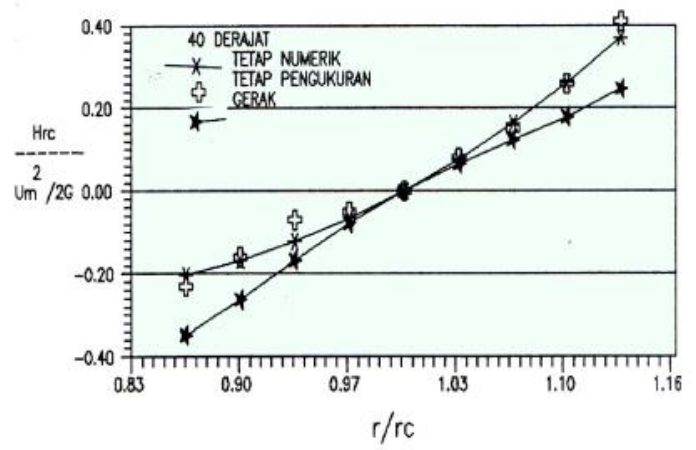

Gambar 8. Profil muka air melintang pada sudut $40^{\circ}$

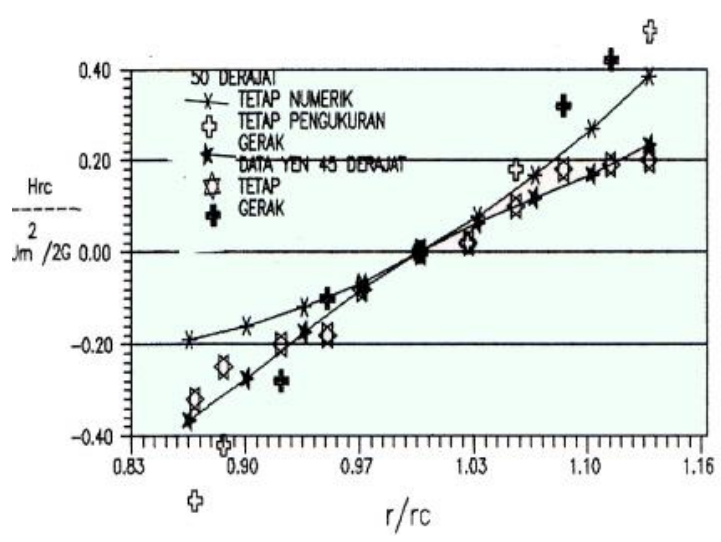

Gambar 9. Profil muka air melintang pada sudut $50^{\circ}$ 


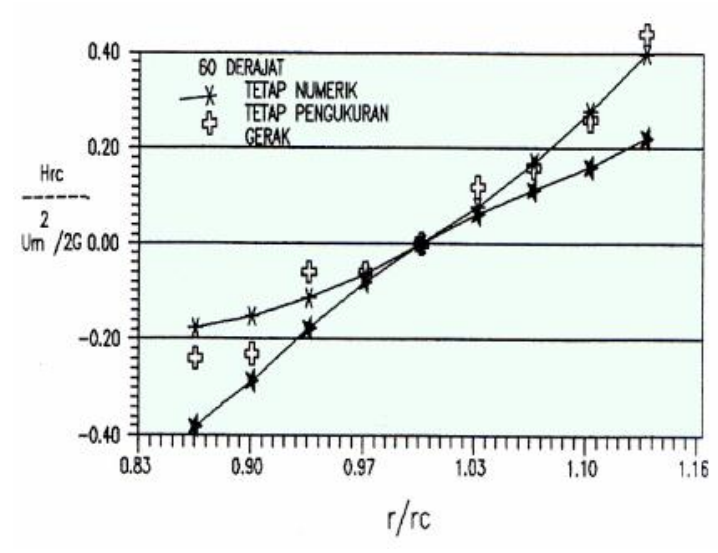

Gambar 10. Profil muka air melintang pada sudut $60^{\circ}$

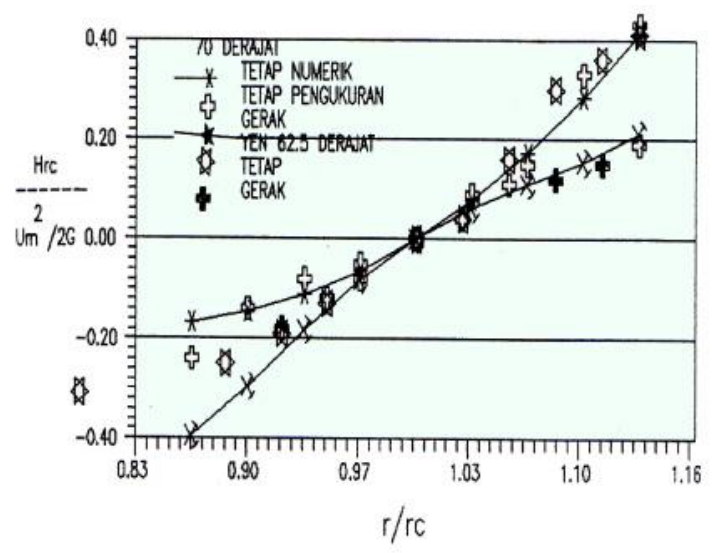

Gambar 11. Profil muka air melintang pada sudut $70^{\circ}$

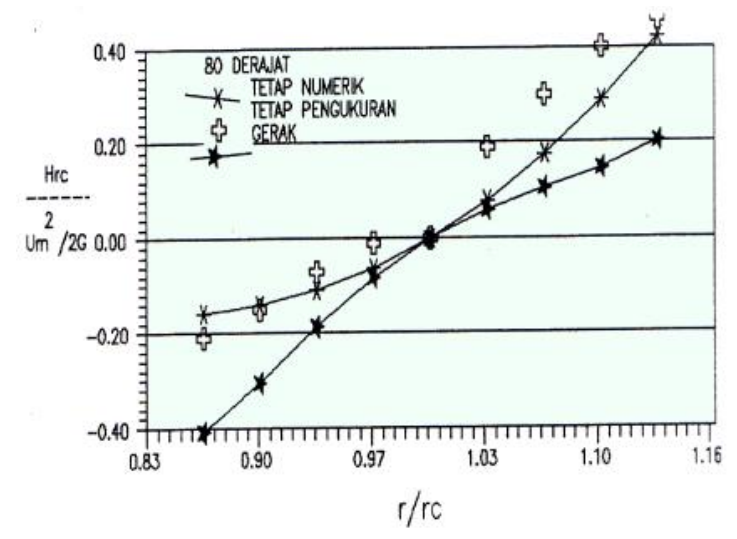

Gambar 12. Profil muka air melintang pada sudut $80^{\circ}$

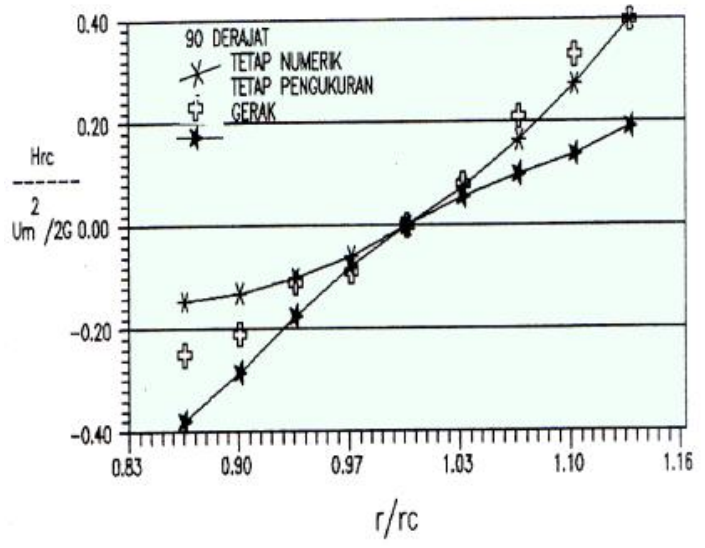

Gambar 13. Profil muka air melintang pada sudut $90^{\circ}$
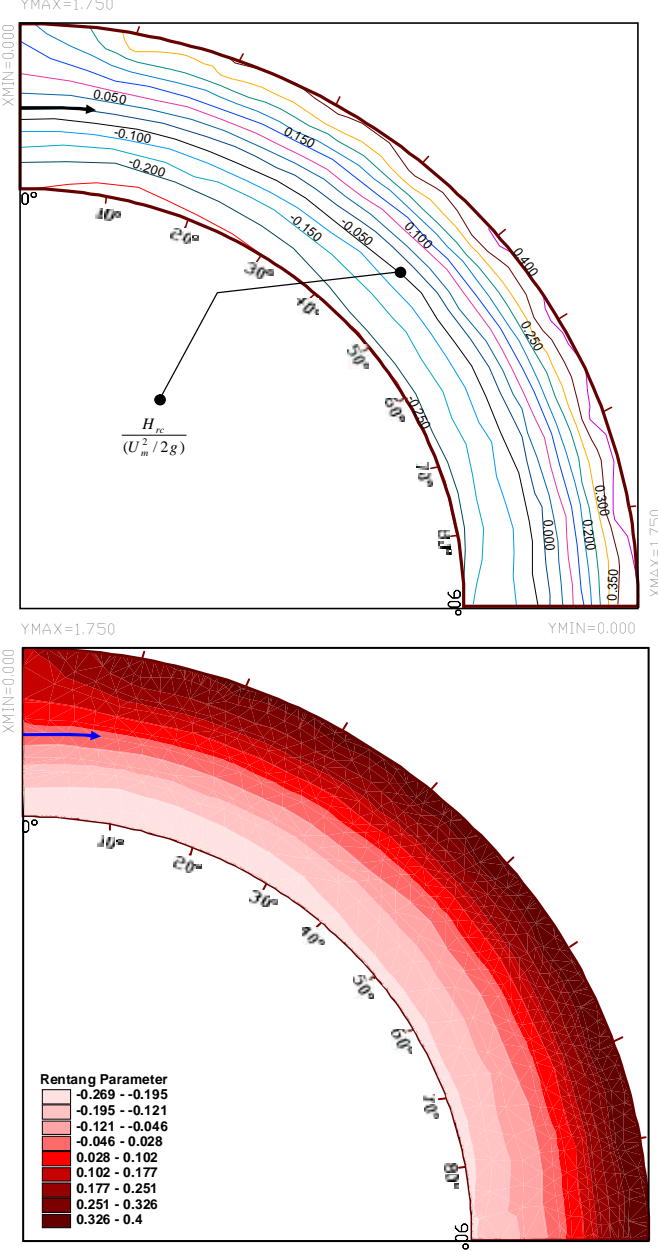

Gambar 14. Kontur permukaaan air di belokan saluran 


\subsection{Fenomena gerusan di Sungai Palu}

Sungai Palu bagian hilir sepanjang kurang lebih $5 \mathrm{~km}$ terukur dari muara, memiliki kemiringan dasar relatif landai, rata-rata sebesar 0.001167 (Gambar 7) dengan lebar sungai berkisar antara $185 \mathrm{~m}$ pada bagian hilir dan berangsurangsur menyempit dengan lebar 89 di sekitar Jembatan 1 .

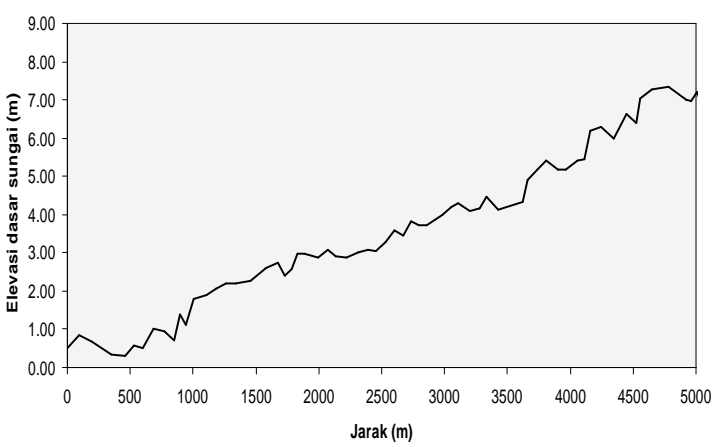

Gambar 15. Profil memanjang Sungai Palu hilir

Gerusan di Sungai Palu terjadi secara umum terjadi pada ruas bagian hilir. Secara khusus gerusan intensif terjadi pada sisi talud sebelah luar belokan di dua lokasi yakni berjarak sekitar $200 \mathrm{~m}$ di sebelah hilir Jembatan 1 dan sekitar $400 \mathrm{~m}$ di sebelah hulu Jembatan 1, dengan sudut belokan (sudut dalam) masing-masing $135^{\circ}$ dan $145^{\circ}$ yang dapat dinyatakan dengan indeks meander, yakni perbandingan antara panjang total alinemen sungai dan panjang total kurvatur sungai. Sungai lurus memiliki indeks meander sama dengan satu. Semakin tinggi angka indeks meander sungai maka sudut belokan dalam akan semakin kecil dan sebaliknya. Pada prinsipnya sungai meander digolongkan sebagai suatu sungai yang membentuk fungsi sinus (Jansen, 1979 dalam Mudjiatko, 2000), yang dibedakan menjadi dua jenis yakni irregular meander dan regular meander. Irregular meander meander diistilahkan untuk sungai yang mempunyai kurva belokan yang tidak teratur antara satu belokan dan belokan yang mengikutinya dan regular meander diperuntukkan untuk sungai yang mempunyai kurvatur seragam.

Pengaruh yang ditimbulkan belokan terhadap aliran adalah terjadinya pembendungan aliran akibat terhambatnya aliran pada salah satu sisi saluran yakni sisi bagian luar belokan
(Mudjiatko, 2000). Peristiwa pembendungan akan menimbulkan terjadinya peningkatan elevasi muka air. Selain itu juga terjadi peningkatan elevasi muka air pada sisi luar belokan akibat gaya sentrifugal yang bekerja pada aliran. Hasil penelitian yang dilakukan oleh Mudjiatko (2000) menunjukkan semakin besar angka indeks meander maka tingkat pembendungan aliran semakin tinggi. Berpijak pada hasil penelitian tersebut dapat disimpulkan bahwa kondisi belokan Sungai Palu merupakan salah satu faktor penyebab banjir di Sungai Palu. Pengaruh lainnya adalah terjadinya pengikisan pada bagian luar belokan dan pengendapan pada bagian dalam belokan, sehingga pada bagian ini bentuk penampang selalu berubah-ubah.

Gerusan talud di Sungai Palu dimulai dengan meningkatnya elevasi muka air pada sisi luar belokan sampai akhirnya elevasi talud terlampaui. Fenomena ini mengakibatkan pengikisan talud yang dimulai dari bagian atas dan berlanjut secara kontinyu pada kaki talud. Akumulasi gaya aliran yang bekerja pada sisi talud menyebabkan talud Sungai Palu dis ekitar belokan mengalami keruntuhan dan kegagalann.

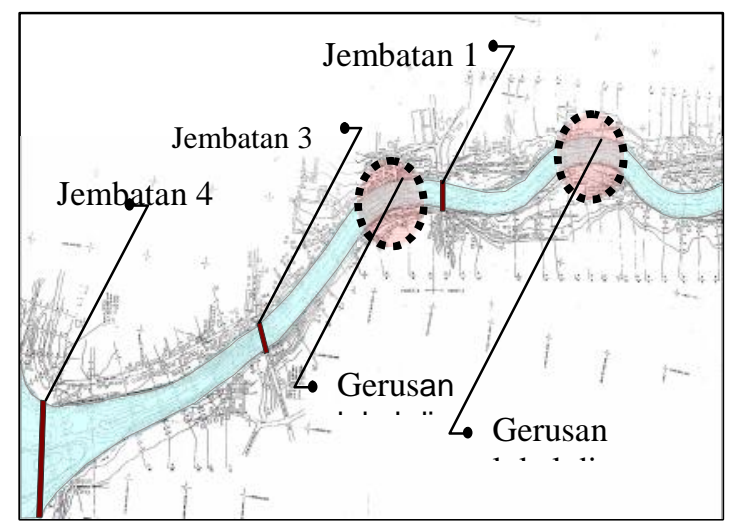

Gambar 16. Situasi dan posisi gerusan talud Sungai Palu hilir

\section{Kesimpulan dan Saran}

\subsection{Kesimpulan}

Berdasarkan analisis yang telah dilakukan maka dapat disimpulkan hal-hal sebagai berikut:

a. Kenaikan muka air di belokan saluran/sungai dapat diidentifikasi dari bilangan Froude. Pada bilangan Froud yang kecil perbedaan ketinggian muka air kecil dan pada bilangan 
Froude yang besar menununjukkan ketinggian muka air yang besar.

b. Kenaikan permukaan air di belokan sungai berbanding lurus terhadap kecepatan.

c. Kasus gerusan di Sungai Palu, terjadi akiabat kenaikan muka air yang besar di belokan sehingga elevasi talud/tanggul terlampaui.

\section{Daftar Pustaka}

Ishak, Galib., (1992), Superelevasi Pada Tikungan Saluran, Tesis S-2 Institut Teknologi Bandung (ITB), Bandung

Jansen, P.P., Berg, V.B., Vries M.D., and Zanen, A., (1979), Principle of River Engineering : The Non-Tidal Alluvial River. Pitman Press, London.

Legono D., (2003), Bahan Kuliah Teknik Sungai, Program S-2 UGM, Yogyakarta

Mudjiatko (2000), Pengaruh Meander Sungai Terhadap Perubahan Konfigurasi Dasar dan Seleksi Butiran Sedimen, Tesis S2 UGM, Yogyakarta.

Yen C. L. (1`971), Water Surface Configuration in Channel Bends, Journal of the Hydraulics Division, Proceding of the American Sociaty of Civil Enginners. 